06

\title{
Электроконтактный материал на основе серебра, дисперсноупроченный оксидами цинка, олова и титана
}

\author{
(ㄷ Г.М. Зеер, ${ }^{1}$ Е.Г. Зеленкова, ${ }^{1}$ А.В. Сидорак, ${ }^{2}$ В.В. Белецкий, ${ }^{1}$ С.В. Николаев, ${ }^{1}$ В.В. Колот, ${ }^{1}$ М.Ю. Кучинский ${ }^{1}$ \\ ${ }^{1}$ Сибирский федеральный университет, \\ 660041 Красноярск, Россия \\ ${ }^{2} \mathrm{OAO}$ „Красцветмет“, \\ 660027 Красноярск, Россия \\ e-mail: g-zeer@mail.ru
}

Поступило в Редакцию 27 июня 2018г.

В окончательной редакции 18 февраля 2020 г.

Принято к публикации 19 февраля 2020 г.

Получен новый электроконтактный материал на основе серебра, дисперсноупрочненный нанопорошками оксидов цинка, олова и титана. Методами электронной микроскопии и энергодисперсионного микроанализа исследованы микроструктура и элементный состав фаз, формирующихся как при твердофазном спекании, так и при электроэрозионных испытаниях. В процессе лабораторных испытаний определен электроэрозионный износ и рассчитано переходное электросопротивление. Разработанный электроконтактный материал показал физико-механические и эксплуатационные свойства, подобные свойствам промышленного контакта, полученного с использованием токсичного оксида кадмия.

Ключевые слова: нанопорошки, электроконтактные материалы, микроструктура, электроэрозионный износ.

DOI: 10.21883/JTF.2020.08.49540.294-18

\section{Введение}

Электроконтактные материалы должны сочетать такие физико-механические и эксплуатационные свойства, как эрозионная и коррозионная стойкость, твердость, высокие электро- и теплопроводность, низкое переходное электросопротивление, возникающее при замыкании контактов $[1,2]$. Этим требованиям удовлетворяют полученные методом порошковой металлургии композиционные электроконтактные материалы на основе серебра или меди с дисперсноупрочняющими и дугогасящими добавками порошков металлов, оксидов, боридов, карбидов металлов и их различных сочетаний в составе исходной смеси [3-18]. При создании бескадмиевых материалов для электроконтактов исследуется влияние на физико-механические и эксплуатационные свойства таких добавок. Распространенной дугогасящей добавкой в составе промышленных электроконтактных материалов является оксид кадмия [2], однако он обладает высокой летучестью и токсичностью. Поэтому существует необходимость замены его на другие компоненты, при этом альтернативой могут выступать оксид цинка $[3,4,6,7,18,19]$ и оксид олова [9-15], которые имеют подобные физико-химические свойства. Кроме того, в настоящее время исследуется возможность использования и изучаются свойства электроконтактных материалов с такими дисперсноупрочняющими и дугогасящими добавками, как сочетание оксида олова или оксида цинка с другими компонентам, например, $\mathrm{Ti}, \mathrm{Hg}, \mathrm{Bi}, \mathrm{Ce}$, $\mathrm{In}_{2} \mathrm{O}_{3}[1,2,13-17]$.
Износ контактов вследствие массопереноса, испарения и разбрызгивания материала при размыкании электрической цепи (дуговая эрозия) обусловлен дуговым разрядом и является главным фактором, определяющим качество электроконтактного материала. Дуговая эрозия сопровождается процессами взаимодействия твердого и жидкого металла с компонентами атмосферы и плазмой дуги с образованием оксидов и других плохопроводящих соединений. Механическое взаимодействие поверхностей контактов осуществляется на отдельных участках, от площади которых и наличия поверхностных пленок в значительной степени зависит переходное электросопротивление. Повышение переходного электросопротивления в сочетании с дугой, возникающей при размыкании контактов, вызывает их разогрев в отдельных точках поверхности, вследствие чего происходит рекристаллизация и разупрочнение материалов, формируется рабочий слой с измененной микроструктурой и составом фаз [2].

Повышение надежности и долговечности контактов может быть достигнуто уменьшением количества керамической составляющей. В частности, применение добавок оксидов в виде нанопрошков позволит уменьшить их весовое количество, повысить дисперсность оксидных фаз в структуре материала, при этом увеличить прочность и твердость матричного материала и сохранить электропроводность практически на уровне чистого серебра. Так как все свойства электроконтактных материалов структурно чувствительны, то при разработке новых составов необходимо учитывать влияние размеров и равномерности распределения компонентов в порошковой смеси, наличия и размеров пор и формирующихся в 
Таблица 1. Состав и свойства электроконтактных материалов

\begin{tabular}{|c|c|c|c|c|c|c|c|c|c|}
\hline \multirow{2}{*}{ Обозначение } & \multicolumn{5}{|c|}{ Содержание элемента, wt.\% } & \multirow{2}{*}{$\begin{array}{l}\text { Пористость } \\
\text { образцов, \% }\end{array}$} & \multirow{2}{*}{$\begin{array}{c}\text { Микро } \\
\text { твердость, МРа }\end{array}$} & \multirow{2}{*}{$\begin{array}{c}\text { Переходное } \\
\text { электросопротивление, } \Omega\end{array}$} & \multirow{2}{*}{$\begin{array}{c}\text { Электроэрозионный } \\
\text { износ, g/cycle }\end{array}$} \\
\hline & $\mathrm{Ag}$ & $\mathrm{ZnO}$ & $\mathrm{TiO}_{2}$ & $\mathrm{SnO}_{2}$ & $\mathrm{CdO}$ & & & & \\
\hline $\mathrm{Z1}$ & 97.9 & 1 & 0.1 & 1 & - & 5.8 & 27 & 0.046 & 0.0124 \\
\hline $\mathrm{Z} 2$ & 96.9 & 2 & 0.1 & 1 & - & 4.7 & 29 & 0.046 & 0.0061 \\
\hline $\mathrm{Z3}$ & 95.9 & 3 & 0.1 & 1 & - & 5.5 & 33 & 0.048 & 0.0132 \\
\hline $\mathrm{Z}$ & 98 & 2 & - & - & - & 2.5 & 21 & 0.043 & 0.0288 \\
\hline $\mathrm{S}$ & 98 & - & - & 2 & - & 5.4 & 20 & 0.043 & 0.0193 \\
\hline $\mathrm{SZ}$ & 98 & 1 & - & 1 & - & 4.8 & 23 & 0.044 & 0.0211 \\
\hline COK-12 & 88 & - & - & - & 12 & 2.5 & 44 & 0.047 & 0.0211 \\
\hline
\end{tabular}

структуре спеченного компакта при твердофазном спекании фаз на физико-механические и эксплуатационные свойства $[19,20]$. Целью настоящей работы является исследование эффективности введения в состав бескадмиевого электроконтактного материала на основе серебра комплексной дугогасящей и дисперсно-упрочняющей добавки, состоящей из нанопорошков оксидов цинка, олова и титана.

\section{Объекты и методики исследований}

Для изготовления образцов использовали порошок $\mathrm{Ag}$ и нанопорошки $\mathrm{SnO}_{2}, \mathrm{TiO}_{2}, \mathrm{ZnO}$. Как было показано в наших предыдущих работах $[4,21]$, порошок серебра имеет средний размер частиц $d_{\mathrm{av}} \approx 5 \pm 3 \mu \mathrm{m}$, нанопорошки оксида олова $-70 \pm 10 \mathrm{~nm}$, оксида титана $20 \pm 5 \mathrm{~nm}$ и оксида цинка $8 \pm 2 \mathrm{~nm}$.

Для получения однородной смеси порошки смешивали в течение $10 \mathrm{~min}$ твердосплавными шарами в вибрационной мельнице RETSCH MM 400. Полученную смесь прессовали в жесткой матрице при давлении $300 \mathrm{MPa}$ в образцы с размерами: диаметр $8 \mathrm{~mm}$, высота $3 \mathrm{~mm}$. Спекание проводили в муфельной печи DAIHAN FH-05 на воздухе при температуре $840^{\circ} \mathrm{C}$ в течение $2 \mathrm{~h}$. Спеченные образцы для повышения плотности допрессовывали при давлении $1000 \mathrm{MPa}$ и для снятия остаточных напряжений отжигали при температуре $500^{\circ} \mathrm{C}$ в течение $1 \mathrm{~h}$.

Микроструктуру и элементный состав образцов исследовали методами сканирующей электронной микроскопии и энергодисперсионного микроанализа с помощью микроскопа JEOL JSM-7001F с системой микроанализаторов Oxford Instruments. Плотность определяли методом гидростатического взвешивания. Микротвердость измеряли вдавливанием четырехгранной алмазной пирамиды с квадратным основанием на приборе ПМТ-3, нагрузка на индентор составляла 0.02 N. Испытания на электроэрозионный износ и измерение переходного сопротивления проводили на специальном лабораторном стенде при переменном напряжении на контактах -

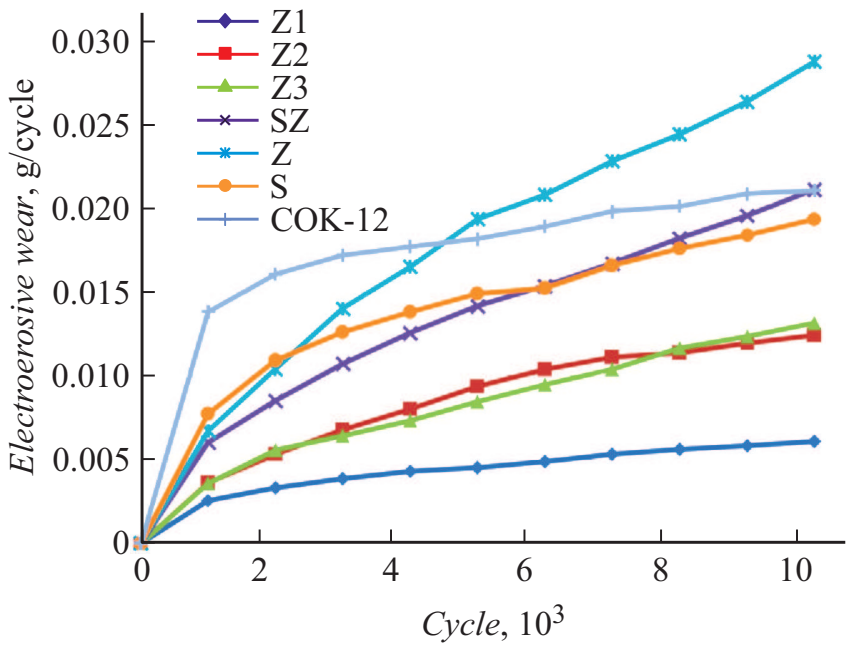

Рис. 1. Электроэрозионный износ разработанных бескадмиевых электроконтактных материалов на основе серебра в сравнении с промышленными образцами СОК-12.

$380 \mathrm{~V}$, частоте $50 \mathrm{~Hz}$, переменном токе - 20 А и общем числе циклов „включение-выключение“, равном 10000 [22]. Износ оценивали измерением массы контактных элементов с держателями на аналитических весах Mettler Toledo AB204-S/Fast до и после испытаний через 1000 циклов. Переходное сопротивление измеряли на 25 -м замыкании электроконтактов в течение $10 \mathrm{~s}$.

\section{Результаты и обсуждение}

В качестве дугогасящих и дисперсноупрочняющих добавок в электроконтактные материалы на основе серебра вводили нанопорошки оксида цинка, оксида олова, а также комплексную добавку, состоящую из нанопорошков оксидов цинка, олова и титана [23-28]. Использование нанопорошков позволяет уменьшить весовое количество оксидов в составе образцов в 3-4 раза, что снижает их влияние на электропроводность образца в целом. 

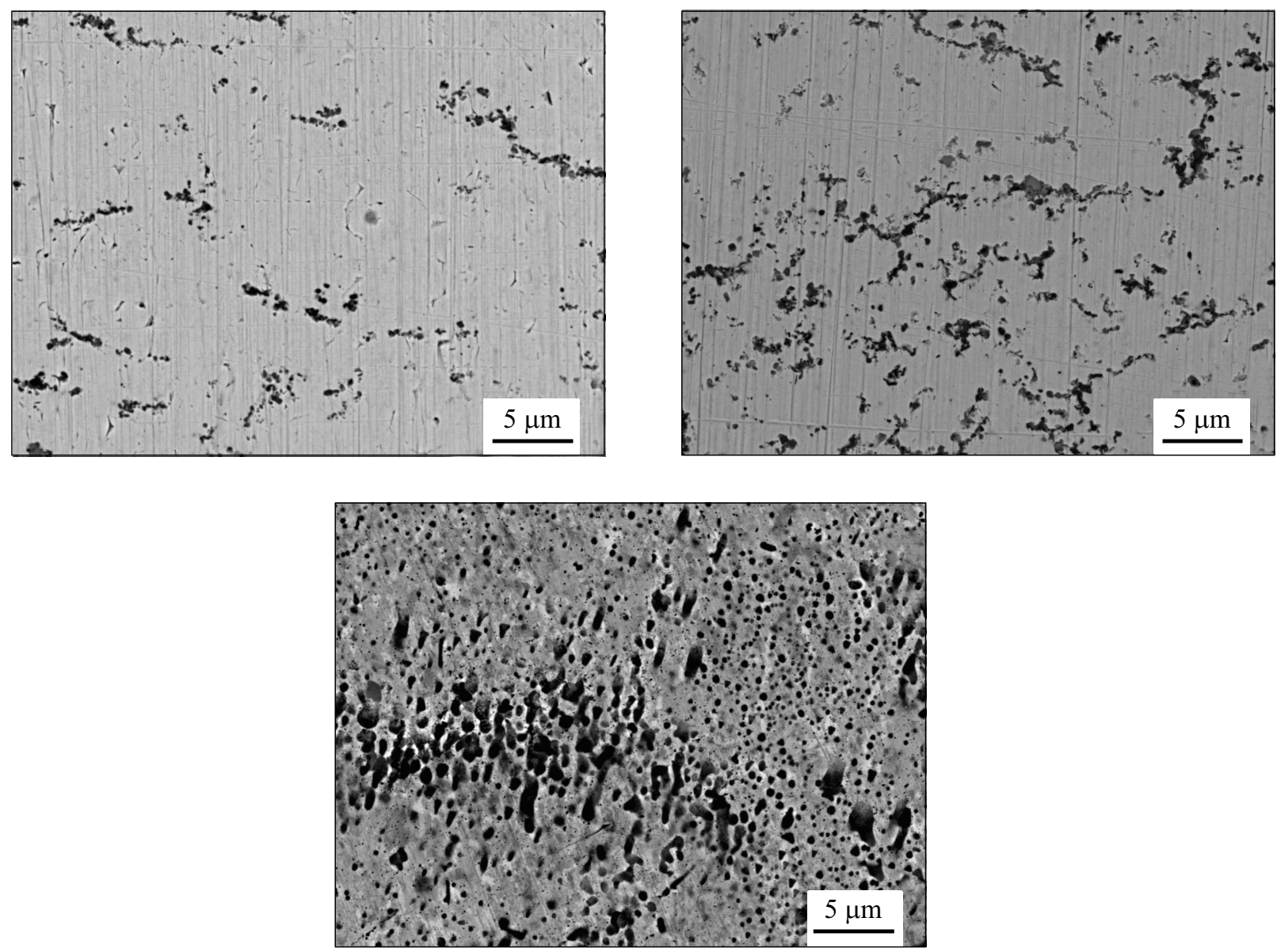

Рис. 2. Электронно-микроскопическое изображение микроструктуры спеченных образцов: $a-\mathrm{Z} 1 ; b-\mathrm{Z} 3 ; c-\mathrm{COK}-12$.

Составы разрабатываемых электроконтактных материалов приведены в табл. 1. При применении комплексной добавки в процессе спекания образцов контактов происходит твердофазное взаимодействие оксидов олова и цинка, а также оксидов титана и цинка в соответствии с диаграммами фазового состояния с образованием новых фаз. Как было показано нами ранее методом РФА [26], результаты взаимодействия становятся заметными после изотермической выдержки уже при $T=800^{\circ} \mathrm{C}-$ оксиды титана и цинка взаимодействует с образованием мета- $\left(\mathrm{ZnTiO}_{3}\right)$ и орто- $\left(\mathrm{Zn}_{2} \mathrm{TiO}_{4}\right)$ титаната цинка, оксиды $\mathrm{ZnO}$ и $\mathrm{SnO}_{2}$ образуют $\mathrm{ZnSnO}_{3}$. Кроме того, остается некоторое количество отдельных агломератов $\mathrm{ZnO}$ и $\mathrm{TiO}_{2}$ вследствие неравномерного распределения оксидов при смешивании порошков серебра и нанопорошков оксидов.

Микроструктура, элементный состав фаз спеченных образцов, физико-механические свойства образцов разработанных составов исследованы в сравнении со свойствами и микроструктурой промышленного электроконтакта СОК-12, результаты представлены в табл. 1. В составе СОК-12 в качестве дугогасящей и дисперсноупрочняющей составляющей содержится 12 wt.\% токсичного оксида кадмия.
Испытания на эрозионный износ промышленного электроконтакта и разработанных электроконтактных материалов, проведенные в одинаковых лабораторных условиях, показали, что состав Z обладает небольшим превышением износа по сравнению с промышленным образцом СОК-12, образцы составов Z2, Z3, Z, S, SZ показали сопоставимую с промышленным образцом СОК-12 электроэрозионную стойкость. Минимальный электроэрозионный износ (почти в 3.5 раза меньше в сравнении с промышленным СОК-12) показали образцы состава Z2 (табл. 1, рис. 1).

Анализ полученных результатов показал, что с повышением содержания оксидной фазы незначительно и нелинейно увеличивается микротвердость вследствие наличия оксидов, обладающих более высокой твердостью, чем серебро, однако она остается существенно меньше микротвердости СОК-12, так как содержание оксидов в нем в 3-6 раз больше. Переходное сопротивление в зависимости от состава практически не изменяется, что подтверждается такими постоянными и контролируемыми параметрами, как усилие прижима, форма и состояние соприкасающихся поверхностей.

Электронно-микроскопические изображения типичной микроструктуры спеченных электроконтактных образ- 

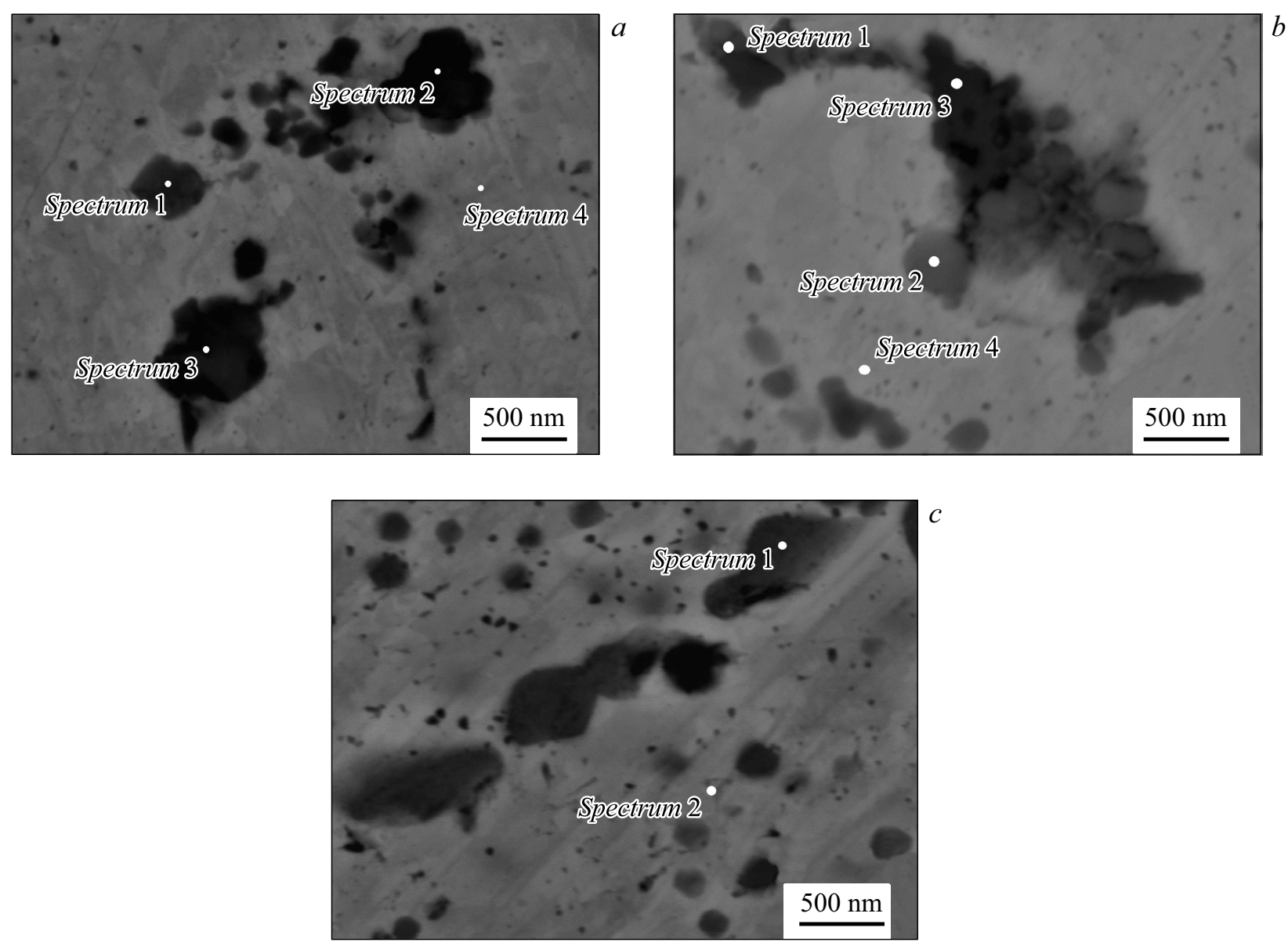

Рис. 3. Электронно-микроскопические изображения микроструктуры спеченных образцов: $a-\mathrm{Z2} ; b-\mathrm{ZS} ; c-\mathrm{COK}-12$. Tочками отмечены области проведения энергодисперсионного микроанализа.

цов, полученные с применением метода композиционного контраста, представлены на рис. 2, a, b. Анализ микроструктуры показал, что оксидные включения (зерна темно-серого цвета) размером от $0.3 \pm 0.1 \mu \mathrm{m}$ равномерно распределены по границам зерен серебра (светлосерого цвета) размером от $15 \pm 5 \mu \mathrm{m}$. С увеличением содержания оксидов в составе образца растет размер отдельных оксидных включений, они выстраиваются в более длинные цепочки, не образующие сплошного каркаса (рис. 2, $a, b)$.

В серебряной матрице промышленного электроконтакта СОК-12 включения оксида кадмия представлены двумя типами: 1 - округлые включения размером около $0.5 \mu \mathrm{m} ; 2$ - включения вытянутой формы, имеющие размеры $1-3 \mu \mathrm{m}$ (рис. 2,c). В структуре образцов разработанных составов размер оксидных включений находится в диапазоне от 0.1 до $0.5 \mu \mathrm{m}$ (рис. 2, $a, b$ ), тогда как в структуре СОК-12 оксидные включения крупнее и достигают $3 \mu \mathrm{m}$. Пористость спеченных образцов в зависимости от состава изменяется, однако ее величина незначительна, что объясняется небольшим количеством добавок нанопорошков и оптимально подобранным технологическим режимом изготовления образцов.
Таблица 2. Элементный состав фаз спеченных образцов электроконтактов (рис. 3)

\begin{tabular}{c|c|c|c|c|c|c|c}
\hline \multirow{2}{*}{ Образец } & \multirow{2}{*}{ Спектр } & \multicolumn{6}{|c}{ Содержание химического элемента, at.\% } \\
\cline { 3 - 8 } & & $\mathrm{O}$ & $\mathrm{Ti}$ & $\mathrm{Zn}$ & $\mathrm{Sn}$ & $\mathrm{Cd}$ & $\mathrm{Ag}$ \\
\hline $\mathrm{Z2}$ & 1 & 45.1 & 1.1 & 25.7 & 1.9 & - & 26.1 \\
\cline { 2 - 8 } & 2 & 45.6 & 0.7 & 28.9 & - & - & 24.8 \\
\cline { 2 - 8 } & 3 & 55.2 & 0.7 & 11.7 & 6.3 & - & 26.1 \\
\cline { 2 - 8 } & 4 & - & - & - & - & - & 100 \\
\hline \multirow{7}{*}{$\mathrm{ZS}$} & 1 & 40.7 & - & 21.2 & 2.9 & - & 35.2 \\
\cline { 2 - 8 } & 2 & 28.5 & - & - & 5.4 & - & 66.0 \\
\cline { 2 - 8 } & 3 & 44.9 & - & 26.9 & 2.1 & - & 26.1 \\
\cline { 2 - 7 } & 4 & - & - & - & - & - & 100 \\
\hline \multirow{2}{*}{ COK-12 } & 1 & 40.2 & - & - & - & 31.3 & 28.2 \\
\cline { 2 - 7 } & 2 & - & - & - & - & - & 100 \\
\hline
\end{tabular}



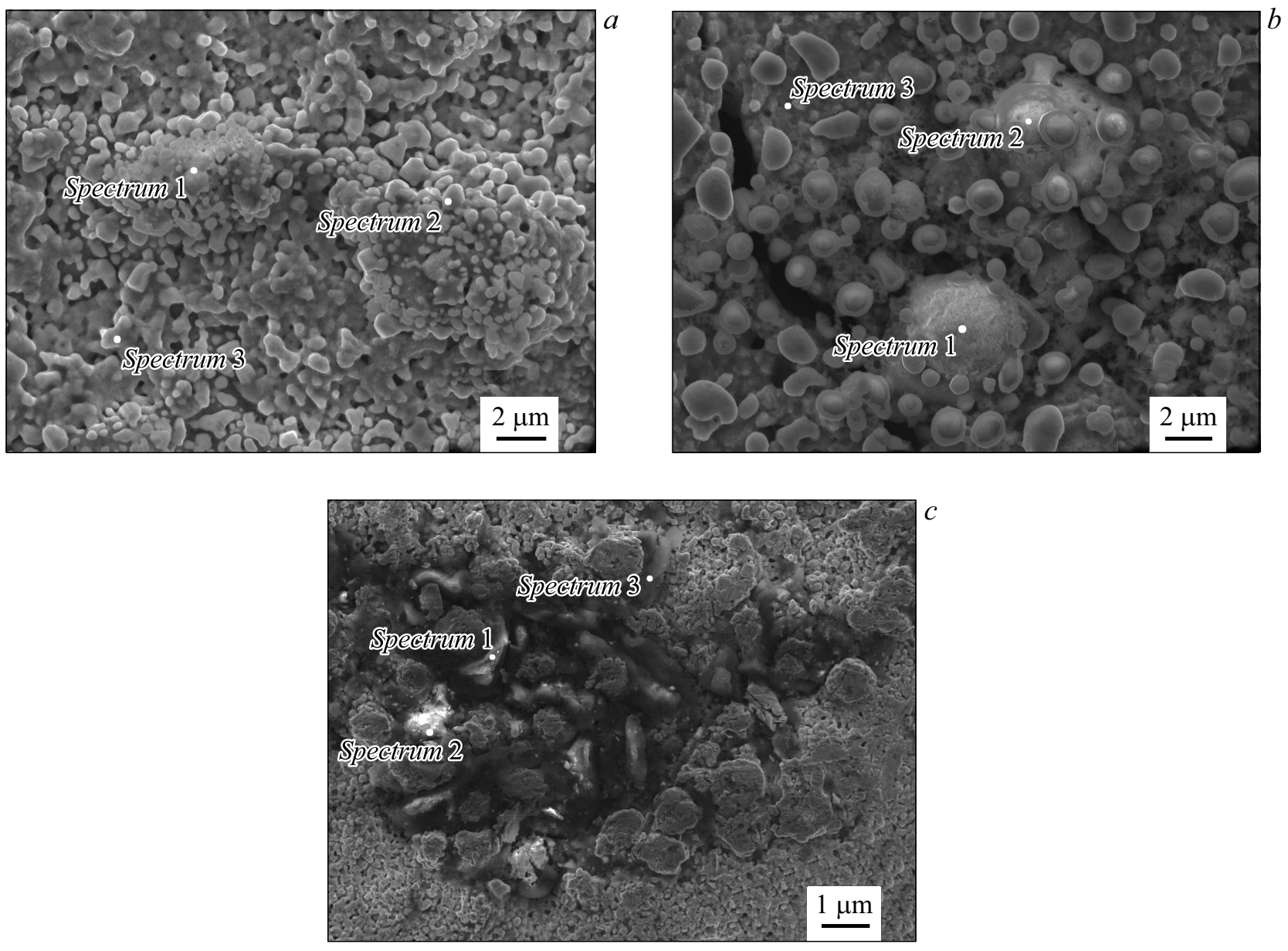

Рис. 4. Электронно-микроскопические изображения рабочей поверхности образцов: $a-\mathrm{Z} 2 ; b-\mathrm{ZS} ; c-\mathrm{COK}-12$. Tочками отмечены области проведения энергодисперсионного микроанализа.

Таблица 3. Элементный состав фаз рабочей поверхности электроконтактов после испытаний (рис. 4)

\begin{tabular}{|c|c|c|c|c|c|c|c|c|c|c|c|c|}
\hline \multirow{2}{*}{ Образец } & \multirow{2}{*}{ Спектр } & \multicolumn{11}{|c|}{ Содержание химического элемента, at.\% } \\
\hline & & $\mathrm{O}$ & $\mathrm{Ti}$ & $\mathrm{Zn}$ & $\mathrm{Cd}$ & $\mathrm{Ag}$ & $\mathrm{Sn}$ & $\mathrm{Si}$ & $\mathrm{Na}$ & $\mathrm{C}$ & $\mathrm{S}$ & $\mathrm{K}$ \\
\hline \multirow[t]{3}{*}{$\mathrm{Z} 2$} & 1 & 40.3 & & 4.6 & - & 53.7 & - & 1.36 & - & - & - & - \\
\hline & 2 & 16.1 & - & - & - & 83.9 & - & - & - & - & - & - \\
\hline & 3 & 13.5 & - & 2.4 & - & 84.1 & - & - & - & - & - & - \\
\hline \multirow[t]{3}{*}{ ZS } & 1 & 16.6 & - & 2.0 & - & 81.4 & - & - & - & - & - & - \\
\hline & 2 & 11.1 & - & - & - & 88.9 & - & - & - & - & - & - \\
\hline & 3 & 18.5 & - & - & - & 78.2 & - & - & - & - & - & - \\
\hline \multirow[t]{4}{*}{ COK-12 } & 1 & 17.5 & - & - & - & 25.6 & - & - & - & 55.8 & 0.5 & 0.5 \\
\hline & 2 & 51.3 & - & - & 35.90 & - & - & - & - & - & 0.4 & 12.8 \\
\hline & 3 & 20.5 & - & - & 3.77 & 9.2 & - & - & - & 66.1 & - & - \\
\hline & 4 & 26.1 & - & - & 12.80 & 61.1 & - & - & - & - & - & - \\
\hline
\end{tabular}

Для определения состава фаз, сформировавшихся в процессе твердофазного спекания, выполнен энергодисперсионный микроанализ. На рис. 3 представлены типичные электронно-микроскопические изображения образцов COK-12, Z2, и ZS, полученные в композиционном контрасте, с зонами проведения микроанализа. В образцах Z2 обнаружены $\mathrm{O}, \mathrm{Sn}, \mathrm{Zn}$, Ti (образец Z2, рис. 3, $a$; табл. 2, спектры 1-4). Анализ соотношения химических элементов (в at.\%) позволяет предположить в структуре образцов наличие дугогасящих и дисперсноупрочняющих фаз - $\mathrm{ZnO}, \mathrm{SnO}_{2}, \mathrm{ZnTiO}_{3}, \mathrm{Zn}_{2} \mathrm{TiO}_{4}, \mathrm{ZnSnO}_{3}$. Анализ соотношения химических элементов (Ag, O, Sn, $\mathrm{Zn}-$ в at.\%) фаз в структуре образцов ZS показал наличие дугогасящих и дисперсноупрочняющих фаз $\mathrm{ZnO}, \mathrm{SnO}_{2}$ и $\mathrm{ZnSnO}_{3}$ (рис. 3, $b$, табл. 2, спектры 1-3; спектр 4 получен на серебряной матрице). Микроструктура образца СОК-12 состоит из матричного материала $\mathrm{Ag}$ и включений дугогасящего $\mathrm{CdO}$ (рис. 3, c, табл. 2, спектры 1,2).

Спеченные образцы прошли испытания на электроэрозионный износ, после чего были исследованы элементный состав и микроструктура рабочей поверхности 

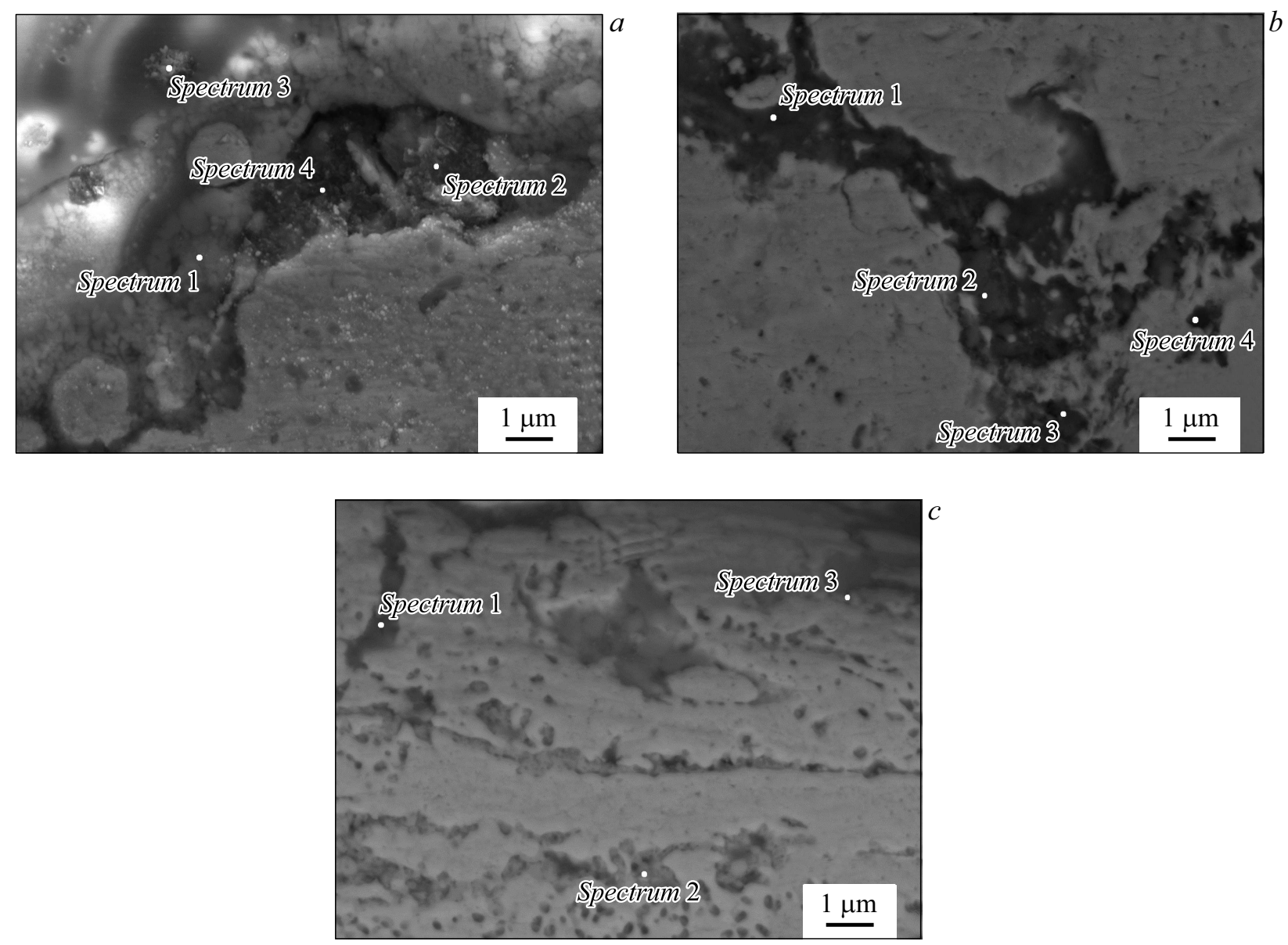

Рис. 5. Электронно-микроскопические изображения поперечного сечения рабочей поверхности образцов: $a-\mathrm{Z2} ; b-\mathrm{ZS} ; c-$ COK-12. Точками отмечены области проведения энергодисперсионного микроанализа.

в двух плоскостях: вид сверху (рис. 4) и поперечное сечение (рис. 5).

При включении-выключении контактов возникает электрическая дуга; происходящие под действием дугового разряда процессы на рабочих поверхностях контактов обусловлены в основном тепловым воздействием, приводящим к расплавлению и окислению материала на рабочей поверхности, а также его испарению, разбрызгиванию и массопереносу. При размыкании в месте плавления идет кристаллизация, появляются выступы и впадины округлой формы (рис. 4), микротрещины (рис. 4, $b$, рис. 5, $a$ ), поры (рис. 4, $a, b$ ). На рабочей поверхности контактов всех составов выявлены участки с исходной структурой, имеющие размеры порядка $100-300 \mu \mathrm{m}$. В структуре поперечного сечения образцов всех составов обнаружены локальные трещины, расположенные параллельно к рабочей поверхности контакта, также определена толщина рабочего слоя, она после 10000 циклов ,замыкание-размыкание“ достигает размеров $30 \pm 10 \mu \mathrm{m}$. Анализ соотношения элементов (в at.\%), обнаруженных в отдельных фазах, свидетельствует о том, что как на поверхности, так и по сечению рабочего слоя присутствуют дисперсноупрочняющие и дугогасящие фазы - $\mathrm{ZnO}, \mathrm{SnO}_{2}, \mathrm{Zn}_{2} \mathrm{TiO}_{4}, \mathrm{ZnSnO}_{3}$.

Серебро - идеальный материал для контактов, но оно склонно к сульфидизации. Образовавшиеся в процессе работы контактов включения дисперсные фазы $\mathrm{Ag}_{2} \mathrm{~S}$ ухудшают работу контактов, снижая прочность и электропроводность, поэтому особое внимание уделено составу фаз, сформировавшихся в процессе испытаний контактов. Элементный состав фаз рабочей поверхности образцов Z1 (максимальные свойства), ZS (минимальные свойства), СОК-12 (промышленный контакт для сравнения) представлен в табл. 3,4. В рабочем слое COK-12 обнаружены Ag, O, Ti, Zn, Sn. Кроме того, в рабочем слое СОК-12 (табл. 4, спектр 3) и Z2 (табл. 4, спектр 4) обнаружены в небольшом количестве $\mathrm{Si}, \mathrm{C}$, $\mathrm{S}, \mathrm{K}$. Эти химические элементы появляются в составе фаз в результате взаимодействия окружающей среды и компонентов материала контакта при высокотемпературном воздействии электрической дуги, например, $\mathrm{Ag}_{2} \mathrm{~S}$. Как свидетельствует литературные данные, эти фазы оказывают отрицательное влияние на электроэрозионный износ электроконтакта в процессе дальнейшей 
Таблица 4. Элементный состав фаз поперечного сечения рабочей поверхности электроконтактов после электроэрозионных испытаний (рис. 5)

\begin{tabular}{|c|c|c|c|c|c|c|c|c|c|c|c|}
\hline \multirow{2}{*}{ Образец } & \multirow{2}{*}{ Спектр } & \multicolumn{10}{|c|}{ Содержание химического элемента, at.\% } \\
\hline & & $\mathrm{O}$ & $\mathrm{Ti}$ & $\mathrm{Zn}$ & $\mathrm{Cd}$ & $\mathrm{Ag}$ & $\mathrm{Sn}$ & $\mathrm{Si}$ & $\mathrm{P}$ & $\mathrm{S}$ & $\mathrm{K}$ \\
\hline \multirow[t]{4}{*}{$\mathrm{Z} 2$} & 157.7 & 0.3 & 13.9 & - & 26.7 & & 1.5 & - & - & - & \\
\hline & 2 & 56.71 & - & 10.9 & - & 20.2 & 9.27 & 2.9 & - & - & - \\
\hline & 3 & 52.9 & - & 9.90 & - & 24.9 & 7.03 & 5.3 & - & - & - \\
\hline & 4 & 54.9 & - & 12.4 & - & 25.3 & 3.24 & 1.9 & - & 2.3 & - \\
\hline \multirow[t]{4}{*}{ ZS } & 1 & 67.4 & - & \begin{tabular}{|l|}
13.7 \\
\end{tabular} & - & 7.6 & 9.54 & 1.3 & - & - & - \\
\hline & 2 & 65.4 & - & 13.6 & - & 12.0 & 7.72 & $\begin{array}{ll}1.4 \\
\end{array}$ & - & - & - \\
\hline & 3 & 61.1 & - & 11.4 & - & 15.6 & 6.92 & 1.0 & - & - & - \\
\hline & 4 & 53.2 & - & 27.3 & - & 16.1 & 3.37 & $7-$ & - & - & - \\
\hline \multirow[t]{3}{*}{ COK-12 } & 1 & 51.4 & - & - & 38.3 & 10.4 & - & - & - & - & - \\
\hline & 2 & - & - & - & 34.7 & 45.4 & - & - & 14.5 & - & 5.4 \\
\hline & 3 & 16.0 & - & - & 9.3 & 72.2 & - & - & - & $|2.5|$ & - \\
\hline
\end{tabular}

эксплуатации. Однако их количество незначительно и, следовательно, их влияние не существенно.

\section{Заключение}

Получены образцы электроконтактных материалов на основе серебра, дисперсноупрочненных комплексными дугогасящими добавками, состоящими из нанопорошков $\mathrm{ZnO}, \mathrm{SnO}_{2}, \mathrm{TiO}_{2}$. Анализ электронно-микроскопических изображений и данных локального элементного состава позволил сделать вывод, что в образцах в результате твердофазного спекания в серебряной матрице формируются следующие фазы: $\mathrm{ZnTiO}_{3}, \mathrm{Zn}_{2} \mathrm{TiO}_{4}, \mathrm{ZnSnO}_{3}$.

Определено, что в процессе испытаний происходит образование сульфидных фаз как в глубине рабочего слоя, так и на поверхности электроконтактов, однако их количество незначительно, что практически не ухудшает дугогасящие свойства.

Полученные электроконтактные материалы имеют низкий электроэрозионный износ, что косвенно подтверждает дисперсно-упрочняющие и дугогасящие свойства предложенной комплексной добавки, состоящей из нанопорошков оксидов цинка, титана и олова.

Анализ результатов испытаний промышленного электроконтакта и разработанных электроконтактных материалов, проведенных в одинаковых лабораторных условиях, показал, что разработанный электроконтактный материал, в составе которого $3.1 \mathrm{wt} \%$ керамической составляющей (2 wt.\% $\mathrm{ZnO}, 1$ wt.\% $\mathrm{SnO}_{2}$ и $0.1 \mathrm{wt} . \%$ $\mathrm{TiO}_{2}$ ), имеет более низкий электроэрозионный износ, чем промышленный, в составе которого содержится 12 wt.\% токсичного оксида кадмия.
Таким образом, показано, что введение в состав бескадмиевого электроконтактного материала на основе серебра комплексной дугогасящей и дисперсноупрочняющей добавки, состоящей из нанопорошков оксидов цинка, олова и титана, является эффективным.

\section{Финансирование работы}

Работа выполнена при частичной финансовой поддержке РФФИ, грант № 16-08-00789 а.

\section{Конфликт интересов}

Авторы заявляют, что у них нет конфликта интересов.

\section{Список литературы}

[1] Holm H. Electric Contacts. Berlin: Springer-Verlang, 2010. $482 \mathrm{p}$.

[2] Гнесин Р.В., Минакова,М.Л., Грекова и др. // Порошковая металлургия. 1995. № 7-8. С. 32-40.

[3] Xu C.-H., Yi D.-Q., Wu C.-P., Wang B., Liu H.-Q., Lu X.-D. // J. Funct. Mater. 2008. Vol. 39. N 8. P. 1306-1309.

[4] Зеер Г.М. // ФММ. 2012. Т. 113. № 9. С. 1-5.

[5] Wu C.P., Yi D.Q., Li J., Xiao L.R., Wang B., Zheng F. // J. Alloy Compd. 2008. Vol. 457. N 1-2. P. 565-570.

[6] Guzmán D., Muñoz P., Aguilar C., Iturriza I., Lozada L., Rojas P.A., Thirumurugan M., Martínez C. // Appl. Phys. A: Mat. Sci. Proc. 2014. Vol. 117. N 2. P. $871-875$.

[7] Sekikawa J., Kubono T. // IEICE Tr. Electron. 2010. Vol. E93C. N 9. P. 1387-1392.

[8] Ćosović V., Talijan N., Živković D., Minić D., Živković Ž. // J. Min. Metall. Sect. B-Metall. 2012. Vol. 48 (1). P. 131-141.

[9] Swingler J., Sumption A. // Rare Metals. 2010. Vol. 29. N 3. P. 248-254.

[10] Krätzschmar A., Herbst R., Mützel T., Niederreuther R., Braumann P. // Proc. of the 56th IEEE Holm Conference on Electrical Contacts. Charleston, SC, USA, 2010. P. 127-133.

[11] Qiao X., Shen Q., Zhang L., Chen L., Fan X., Yang H. // Rare Metal Mat. Eng. 2014. Vol. 43. N 11. P. 2614-2618.

[12] Wang H., Yang Q., Wang J. // Proc. of the 5th International Conference on Reliability of Electrical Products and Electrical Contacts (ICREPEC 2014). Wenzhou, China, 2014. P. 295-299.

[13] Wang J., Li D., Wang Y. // J. Alloy Compd. 2014. Vol. 582. P. $1-5$.

[14] Lim H.N., Nurzulaikha R., Harrison I., Lim S.S., Tan W.T., Yeo M.C. // Int. J. Electrochem. Sci. 2011. Vol. 6. P. 4329-4340.

[15] Zhu Y., Wang J., An L., Wang H. // Rare Metal Mat. Eng. 2014. Vol. 43 (7). P. 1566-1570.

[16] Yancai Z., Jingqin W., Liqiang A., Haitao W. // Adv. Mater. Res. 2014. Vol. 936. P. 486-490.

[17] Zhu Y., Wang J., Wang H., Ding J. // Mater. Sci. Forum. 2014. Vol. 789. P. 270-274.

[18] Kim J.K., Jang D.J., Ju K.I., Lee E.H., Um S.Y., Nam T.W. // J. Korean Inst. Met. Mater. 2008. Vol. 46. N 7. P. 443-448.

[19] Schatt W., Wieters K.-P., Kieback B. Pulvermetallurgie. Technologien und Werkstoffe. Dresden: Springer-Verlag, 2007. 547 p. 
[20] Jiang Y., Liu S.H., Chen J.L., Mao Y., Xie M., Sun X.D. // Mater. Res. Innov. 2015. Vol. 19. N S4. P. 152-156.

[21] Зеер Г.М., Зеленкова Е.Г., Белеикий В.В., Николаев С.В., Кохурин А.Н., Кучинский М.Ю., Григорьева О.А. // ЖТФ. 2015. Т. 85. Вып. 12. С. 88-93.

[22] Ivanov V., Sidorak A., Shubin A., Kotlyarov I. // J. Sib. Fed. Univ. Eng. Technol. 2014. Vol. 7. N 2. P. 229-234.

[23] Николенко А.Н., Пасенко А.А., Пивоваров А.А., Мельников Б.И. // Вопр. химии и хим. технологии. 2010. № 5. C. $102-109$.

[24] Dulin F.H., Rase D.E. // J. Am. Ceram. Soc. 1960. Vol. 43. N 3. P. $125-131$.

[25] Mohammadia M.R., Fray D.J. // J. Eur. Ceram. Soc. 2010. Vol. 30. P. 947-961.

[26] Zeer G.M., Zelenkova E.G., Nikolaeva N.S., Zharkov S.M., Abkaryan A.K., Mikheev A.A. // Sci. Sinter. 2018. Vol. 50. N 2. P. $173-181$.

[27] Yang G., Yan Z., XiaO T. // Appl. Surf. Sci. 2012. Vol. 258. P. 8704-8712.

[28] Kumar S., Gupta M., Sathe V., Shripathi T., Phase D.M., Das B. // Phase Transit. 2015. Vol. 88. N 11. P. 1122-1136. 